DOI: 10.20472/BMC.2020.011.009

\author{
NEETI MATHUR \\ NIIT University, Neemrana, India
}

HIMANSHU MATHUR

Bright Minds Education Society, India

\title{
APPLICATION OF GARCH MODELS FOR VOLATILITY MODELLING OF STOCK MARKET RETURNS: EVIDENCES FROM BSE INDIA
}

\begin{abstract}
:
The National Stock Exchange and Bombay Stock Exchange are the two major stock exchanges in India. The Bombay Stock Exchange is the first stock exchange of Asia and 10th largest stock exchange in the world in the terms of market capitalisation. Stock markets significantly contributes in the economic development of India. The stock markets have volatile character which results into the uncertainty of the returns, volatility is caused by the variability in speculative market prices and the instability of business performance. Volatility plays a significant role in financial decisions of the investors, managers, policy makers and the researchers as it can assess the risk exposures in their investments and the uncertainty in stocks returns. The risk averse investor avoid investment in highly volatile market. The stock return forecasting leads to volatility forecasting.

This paper has made an attempt to analyse the volatility with reference to Bombay Stock Exchange. The daily data of S\&P Sensex 30 has been collected and used to calculate the volatility of stock market in India for last 3 years (April 2016 to March 2019). The preliminary analysis is done on the basis of descriptive statistics Stationery test, Normality test and serial correlation test. Volatility modelling is done by the ARCH and GARCH family models.

The findings of the study will help investors in taking good investment decisions in Indian stock market in the presence of its volatile character.
\end{abstract}

\section{Keywords:}

ARCH Model, Custer Analysis Diversification, Expansion, Generalized ARCH Model (GARCH Model), Growth, Return, Risk

JEL Classification: C55, C19 


\section{Introduction:}

Indian stock market has its prominent position in the globe. In 2018, the healthy economic growth in India has supported its stock market to become the world seventh largest market by the volume of transactions and market-capitalization which is $\$ 2.08$ trillion. India's economic growth will continue to propel higher market capitalization. India's ascent reflects the growing blow of emerging markets. The National Stock Exchange and Bombay Stock Exchange are the two national stock exchanges and NIFTY and SENSEX are two important indices of these stock exchanges respectively.

This paper has made an attempt to analyse the volatility of Stock markets in India. The stock market volatility is reason of concern for the investors, stock brokers and financial analysts hence the study of volatility is important in risk management. Alexander, (1999) stated that the investors and financial analysts are concerned about the uncertainty of the returns on their investment assets, caused by the variability in speculative market prices and the instability of business performance. High volatility leads to uncertainty in returns therefore the investors found it obstacle for investing decisions. There are few studies on GARCH and ARCH modelling of stock return volatility from Indian Stock markets are conducted specially for the last five year duration.

In this research paper the daily data of selected companies from NSE have been collected and used to calculate the volatility of stock market in India for last 3 years (April 2016 to March 2019). The ARCH and GARCH models are applied to study the market volatility.

\section{Volatility and volatility modeling:}

Volatility is defines level of variety of an exchanging trade prices after some time as measured by the standard deviation of profits. Volatility are for knowing risk, allocation of assets, make profit with financial trading. The risk averse investor avoid investment in highly volatile market. The stock return forecasting leads to volatility forecasting.

Examining stock prices volatility fluctuations is prerequisite for investment decisions thus $(\mathrm{ARCH})$ i.e Autoregressive conditional heteroskedasticity, (GARCH) i.e Generalized autoregressive conditional heteroskedasticity models which are stochastic volatility models are used for judging volatility.

\section{Literature review:}

Engle (1982) introduced the autoregressive conditional Heteroskedasticity $(\mathrm{ARCH})$ to model volatility through linking the conditional variance of the disturbance term to the linear combination of the squared disturbances in the recent past. Bollerslev (1986) generalized the $\mathrm{ARCH}$ model by modelling the conditional variance to depend on its lagged values as well as squared lagged values of disturbance. Since the works of Engle (1982) and Bollerslev (1986), 
various variants of GARCH model have been developed to model volatility. Nelson (1991) proposed one of the extended ARCH models by using Exponential Generalized Auto Regressive Conditional Heteroscedasticity which is known as (EGARCH) model, to identify the asymmetric shocks of the conditional variance. Campbell and Hentschell (1992), Akgiray (1989) and Balaban (1995) conveyed that return expectation increase due to volatility increase in the stock market.The $\mathrm{ARCH}$ and $\mathrm{GARCH}$ models are fairly useful in the process of forecasting and modeling volatility but they lack in capturing 'leverage effect' and information asymmetry. Ogum, G., Beer, F. and Nouyrigat, G. (2005) and Yaya, O.S., (2013) studied African markets, examine the market volatility using Nigeria and Kenya stock return. The exponential GARCH model indicate that asymmetric volatility found in Nigerian stock market (NSM) as developed markets, while Kenya shows evidence of significant and positive asymmetric volatility.

West and Cho (1995) and Brooks and Burke (1998) explore the out-of-sample predictive ability of several models of exchange rate volatility, using a weekly data set for the period March 1973 to September 1989 and the forecast horizons of 1, 12 and 24 weeks. Bekaert and Harvey (1997) and Aggarwal et al.(1999) in their study of emerging markets volatility, demonstrate that the of asymmetric GARCH models is helpful in finding asymmetry in stock return volatility. Jayasuriya (2002) with the help of symmetric GARCH model observes the effect of stock market liberalization on stock returns and volatility in Nigeria and fourteen other emerging market data, from December 1984 to March 2000. The study found that positive changes in prices have been followed by negative changes in volatility and vice versa. Curto (2002) used the GARCH model to explain the volatility of the Portuguese equity market. Batra (2004) inspected the time varying pattern of stock return volatility with the help of asymmetric GARCH model. He also studied sudden shifts in volatility and the possibility of coincidence of these sudden shifts with substantial domestic and global economic and political events. Karmakar (2005) studied the feature of stock market volatility in India and estimated volatility model and determine the effectiveness of $\mathrm{GARCH}(1,1)$ model to forecast market volatility. The study also investigated the presence of leverage effect in Indian stock market. Walter (2005) applied the structural GARCH model to portfolio risk management while Frimpong and Oteng-Abayie (2006) used the GARCH models to modelling of the Ghana Stock Exchange volatility. Alberg et al. (2006) estimate stock market volatility of Tel Aviv Stock Exchange indices, for the period 1992-2005. They stated that the EGARCH model is the most successful in forecasting the TASE indices. Alberg, D., Shalit, H., \& Yosef, R. (2008), Kumar(2006) Nicholls and David Tonuri (1995) Hojin Lee (2009) (Zivot and Wang, 2006) and Shenbagaraman (2003) Estimated stock market volatility using asymmetric GARCH models. Hojin Lee (2009) studied the advantage of GARCH models and symmetric effect in stock market volatility using GARCH Models on stock market historical prices the results were different from previous theory which 
assert that there are asymmetric effects in the stock market volatility. Modelling volatility will provide better insight about the stock price importance and more precise models for pricing financial assets which will assist managers, investors and policy makers to undertake financial decisions such as raising capital, and some investment decisions in financial markets (Emenike, 2010). Hojatallah and Ramanarayanan (2010) used the BSE 500 index of Mumbai stock exchange to evaluate the volatility of the Indian stock markets and its related stylized facts using $\mathrm{ARCH}$ models. The results suggest that the volatility in the Indian stock market exhibits the persistence of volatility and mean reverting behaviour. Franses, P.H. and Van Dijk, R. (1996), Choo, C.W.C. (1999), Gokcan S., (2000) and Kashif Saleem (2007) had shown that models with a small lag like $\operatorname{GARCH}(1,1)$ is sufficient to cope with the changing variance. Amadeus Wennström (2014) has done volatility forecasting and their performance examination forecasting models; the simple moving average, the exponentially weighted moving average, the ARCH model, the GARCH model, the EGARCH model and the GJRGARCH model. Lastrapes (1989) used a standard ARCH model developed by Engle (1982) and found significant decrease in persistence of shocks to volatility. Nicholls and David Tonuri (1995) focused on the asymmetric GARCH models and estimated the stock market data in Australia. Chen et al. (2008) examined the autocorrelation and conditional volatility of Dow Jones Industrial Average index return data using an exponential asymmetric GARCH model. Emenike and Aleke (2012) inspected the response of volatility to negative and positive news using daily closing prices of the Nigerian Stock Exchange (NSE). They find strong evidence supporting asymmetric effects in the NSE stock returns but with absence of leverage effect. Various time series methods are employed by Tudor (2008), including the simple GARCH model, the GARCH-in-Mean model and the exponential GARCH to investigate the risk-return trade-off on the Romanian stock market. Results of the study confirm that E-GARCH is the best fitting model for the Bucharest Stock Exchange composite index volatility in terms of sample-fit. Zivot and Wang, (2006) has proposed that before estimating a full ARCH model for a financial time series, it is necessary to check for the presence of $\mathrm{ARCH}$ effects in the residuals. If there are no $\mathrm{ARCH}$ effects in the residuals, then the $\mathrm{ARCH}$ model is unnecessary. Dana Alnajjar (2016) attempted to forecast the volatility of Jordan's capital market using GARCH family models. The study comprises of three models i.e ARCH, GARCH and EGARCH to find out volatility clustering, leptokurtosis and leverage effect on Amman stock exchange which showed that ARCH GARCH gives more evidence for both volatility clustering and leptokurtic. Puja Padhi (2006) have studied the volatility of individual stock and of the aggregate indices, using $\mathrm{ARCH}$ model, $\mathrm{GARCH}$ model and $\mathrm{ARCH}$ model from January 1990 to November 2004 of daily data. Balaban, E., Bayar, A. and Faff, R. (2005) studied symmetric and asymmetric $\mathrm{ARCH}$-type models to derive volatility expectations. 


\section{Objectives of the Study:}

The research objectives are as follows:

1. To investigate the volatility pattern of BSE S\&P Sensex 30 with the help of its National Stock Exchange data using $\mathrm{ARCH}$ and $\mathrm{GARCH}$ models.

2. To analyse the fitness of the Autoregressive Conditional Heteroscedastic ARCH and Generalized Autoregressive Conditional Heteroscedastic $(\mathrm{GARCH})$ family models on the research data.

\section{Hypothesis:}

1. HO-Null Hypothesis: There is no ARCH Effect in the data sample of BSE S\&P Sensex 30 index.

2. H0-Null Hypothesis: There is presence of unit root in the data sample of BSE S\&P Sensex 30 index.

3. H0-Null hypothesis: There is a white noise process follow in the data sample of BSE S\&P Sensex 30 index.

\section{Research Methodology:}

\section{Sample Data and Preliminary Analysis:}

The daily data of S\&P Sensex 30 index of Bombay Stock Exchange (BSE) of India is used for analysis. The period is April 2016 to March 2019, total number of observations are 738 excluding public holidays. The S\&P Sensex 30 index is a weighted index of top 30 securities that are listed equities on the BSE. The daily returns are used to generate the continuously compounded returns used in the $\mathrm{ARCH}$ and $\mathrm{GARCH}$ modelling.

\section{Concept of Return}

Return can be defined as the actual income from the security as well as appreciation in the value of initial investment. Hence there are two components in return interest or dividends and the change in the price of the asset, commonly called as the capital gain or loss.

It is measured as: Total Return = Dividend or Interest Received + Price change in assets over the period /Purchase price of the asset.

\section{Calculation of Return:}

In this research paper daily closing price (Friday closing) of the stocks of S\&P SENSEX 30 of BSE for the selected period have been used for calculating \%.

$$
Y=\left(\frac{P_{n+1}-P_{n}}{P_{n}}\right) \times 100
$$


where $Y_{i}$ is daily return on the stock, $P_{i+1}$ is Price (Friday closing) of the stock in the (i+1)th day, $P_{i}$ is Price (Friday closing) of the stock in the th day.

\section{Histogram Plot S\&P Sensex 30 Returns}

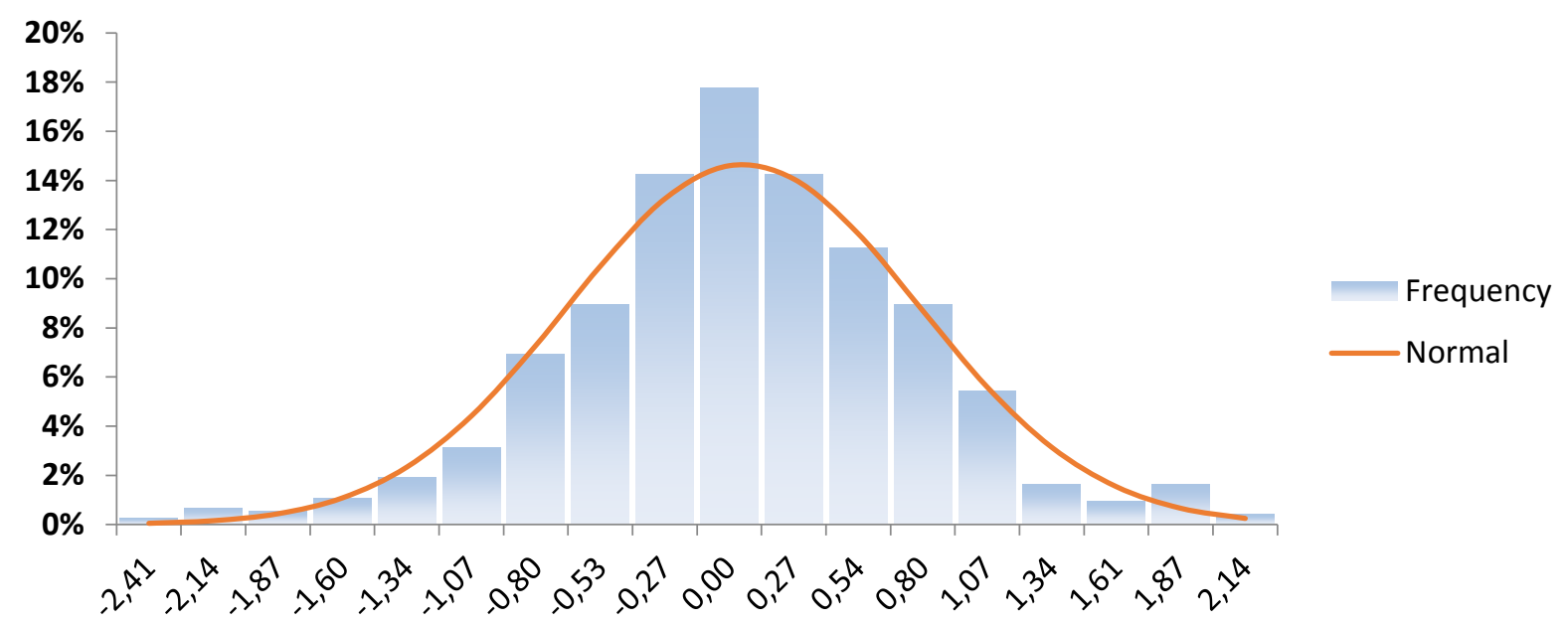

Volatility Clustering Chart: Figure 1.

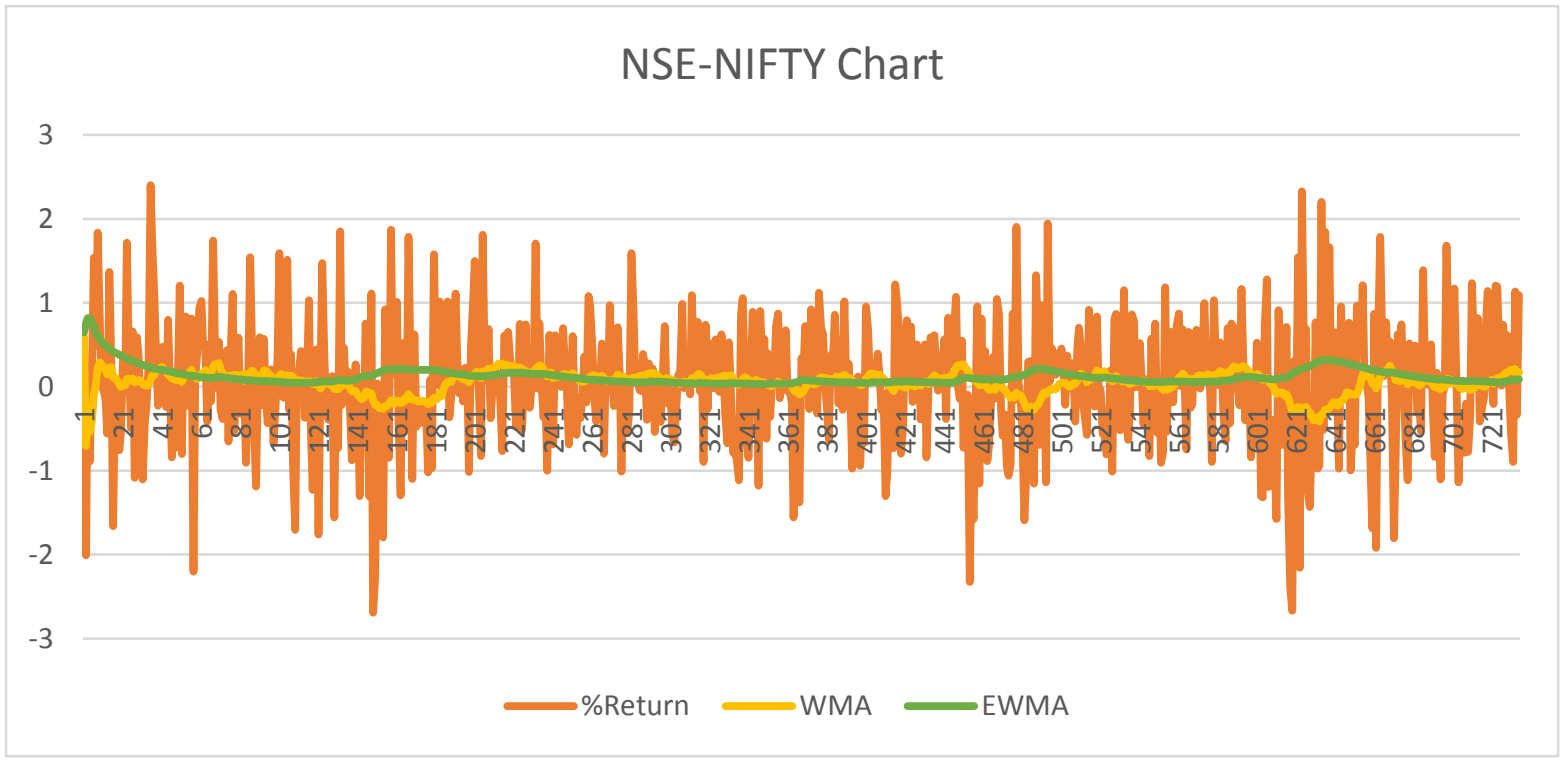

Volatility Clustering Chart Showing volatility on the basis of percentage return of S\&P Sensex 30 index, it is also showing Weighted Moving Average returns and Exponential Moving Average returns.

\section{Descriptive Statistics:}

Table 1. Represents the descriptive statistics of the S\&P Sensex 30 index the daily return of period under study is used. The negative skewness -.19 of S\&P SENSEX 30 implies that the distribution of the variable has a long left tail (mean $<$ median $<$ mode). In other words, the distribution is negatively skewed to the normal distribution. The kurtosis .76 for the S\&P 
SENSEX 30 as the distributions with kurtosis $<3$ hence it is platykurtic, it means the distribution produces fewer and less extreme outliers than does the normal distribution.

\section{Table 1:}

\begin{tabular}{|cc|}
\hline & S\&P \\
& Sensex \\
Summary Statistics & $\mathbf{3 0}$ \\
\hline Average: & 0.06 \\
Standard Deviation: & 0.72 \\
Skew: & -0.19 \\
Excess Kurtosis: & 0.76 \\
Median: & 0.07 \\
Minimum: & -2.54 \\
Maximum: & 2.27 \\
1st Quartile: & -0.36 \\
3rd Quartile: & 0.52 \\
\hline
\end{tabular}

Figure: 2 Histogram is showing normal distribution of the returns.

\section{Quantile-Quantile (Q-Q) Plot}

Along with the descriptive statistics, a Quantile-Quantile (Q-Q) Plot is used to check whether the return series is normally distributed. The $Q-Q$ plot is an empirical graphical device used to check the validity of a distributional assumption for a data set. For the study data the returns are normally distributed hence the $Q-Q$ plot lies on straight line. Table 2 . Figure 2 shows the Q-Q plot of the daily returns series of the S\&P SENSEX 30.

Table 2. and Figure 3:

\begin{tabular}{|c|c|}
\hline S\&P Se & \\
\hline Mean & STDEV \\
\hline 0.0599 & 0.7244 \\
\hline Normal & Empirical \\
\hline-1.335 & -1.280 \\
\hline-0.908 & -0.813 \\
\hline-0.605 & -0.508 \\
\hline-0.349 & -0.304 \\
\hline-0.114 & -0.084 \\
\hline 0.114 & 0.083 \\
\hline 0.349 & 0.324 \\
\hline 0.605 & 0.573 \\
\hline 0.908 & 0.871 \\
\hline 1.335 & 1.238 \\
\hline
\end{tabular}

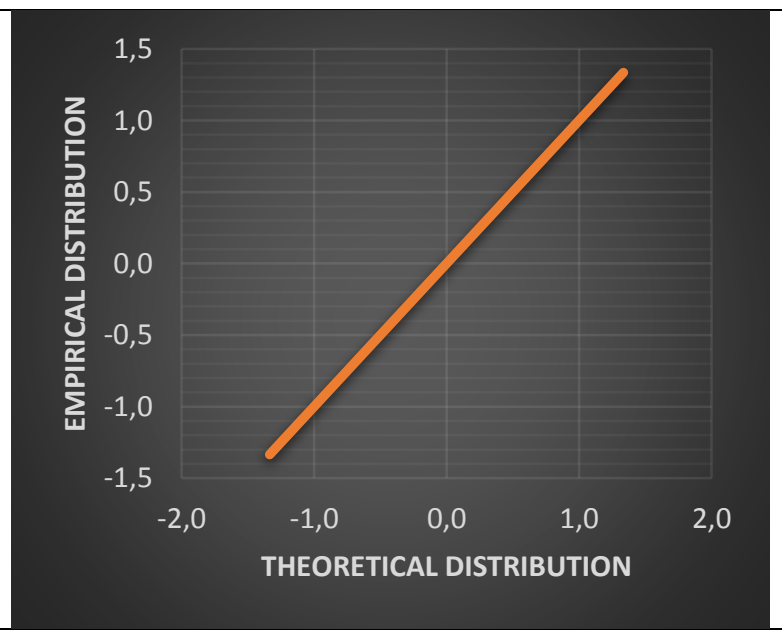

Q-Q Plot S\&P Sensex 30 


\section{Stationary Test:}

Augmented Dickey Fuller (ADF) test (1979) has been conducted to check for the stationary of the collected time series data. The results of the stationary tests for the return series are less than the critical values i.e. $p$ value is . $1 \%$ at $5 \%$ level of significance for Augmented DickeyFuller test, hence the null hypothesis of presence of unit root convincingly rejected and alternative hypothesis is presence of stationarity is accepted.

\section{White Noise Test:}

A time series is white noise if the variables are independent and identically distributed with a mean of zero. This means that all variables have the same variance (sigma^2) and each value has a zero correlation with all other values in the series. The HO hypothesis states that the variable follows a white noise process. The $p$-value is smaller than the significance level, $\alpha$ i.e $5 \%$ means that you reject the null and conclude that the variable is not a white noise. In this study the $\mathrm{p}$-value is $18.07 \% \alpha$ is $5 \%, \mathrm{HO}$ is not rejected this implying that the variable is certainly a white noise process.

\section{Model Specification:}

\section{ARCH Model:}

The first model that provides a systematic framework for volatility modelling is the ARCH Model of Engle (1982). Engle (1982) showed that it is possible to model the mean and the variance of a series simultaneously. As a preliminary step to understanding Engle's methodology, note that conditional forecasts are vastly superior to unconditional forecasts.

The basic idea of $A R C H$ model is that: $(a)$ the shock $a_{t}$ of an asset return is serially uncorrelated but dependent, and (b) the dependence of $\mathrm{a}_{\mathrm{t}}$ can be described by a simple quadratic function of its lagged values. Specifically, an ARCH (1) model assumes that,

$$
a_{\mathrm{t}}=\sigma_{\mathrm{t}} \varepsilon_{\mathrm{t}}, \text { where } \sigma_{t}^{2}=\alpha_{0}+\alpha_{1} a_{t-1}^{2}
$$

Here $\left\{\varepsilon_{t}\right\}$ is a sequence of independent and identically distributed (i.i.d) random variables with mean zero and variance $1, \alpha_{0}>0, \alpha_{1} \geq 0$. The coefficient $\alpha_{1}$ must satisfy some regularity conditions to ensure that the unconditional variance of $a_{t}$ is finite. In practice, $\varepsilon_{t}$ is often assumed to follow the standard normal, or a standardized Student-t distribution, or a Generalized Error Distribution (GED) (Tsay, 2010).

From the structure of the model, it is seen that large past squared shock $a_{t-1}^{2}$, imply a large conditional variance $\sigma_{t}^{2}$ for the innovation $\mathrm{a}_{\mathrm{t}}$. Consequently, $\mathrm{a}_{\mathrm{t}}$ tends to assume a large value. This means that, under the $\mathrm{ARCH}$ framework, large shocks tend to be followed by another 
large shock. Here the word 'tend' is used because a large variance does not necessarily produce a large realization. It only says that, the probability of obtaining a large variance is greater than that of a smaller variance. This feature is similar to the volatility clustering observed in asset returns. In addition, the shock $a_{t}$ of a conditional Gaussian ARCH (1) model is more likely than a Gaussian white noise series to produce 'outliers'. This is in agreement with the finding that 'outliers' appear more often in asset returns than that implied by an i.i.d sequence of normal random variate. (Tse, 2010)

\section{GARCH $(1,1)$ Model:}

The GARCH $(1,1)$ model was developed independently by Bollerslev (1986) and Taylor (1986). The model contains the joint estimation of the mean equation and the conditional variance equation. Bollerslev extended Engle's original work by developing a technique that allows the conditional variance to be an ARMA process.

The mean equation is specified as follows:

Mean equation: $R_{t}=\mu+\varepsilon_{t}$

where

$R_{t}$ is return at time

$\mu$ is the mean of the returns

$\varepsilon$ is the residual return at time $\mathrm{t}$

The return for a month will depend on returns in previous periods (autoregressive component) and the innovation terms in previous periods (moving order component). The $\operatorname{GARCH}(1,1)$ version of the model is:

Conditional variance equations: $\sigma^{2}=\alpha_{0}+\alpha_{1} \varepsilon^{2}{ }_{t-1}+\beta \sigma_{t-1}^{2}$ where

$\sigma^{2}$ is the conditional variance at time

$\alpha_{0}$ is the mean of unconditional variance (long-run average variance)

$\varepsilon^{2}{ }_{t-1}$ is the squared error at time $\mathrm{t}-1$ from the mean equation $(\mathrm{ARCH}$ term)

$\sigma 2 \mathrm{t}-1_{1}$ is the last period' $\mathrm{s}$ forecast variance (GARCH term)

$\alpha_{1}$ is the first (lag 1) ARCH parameter

$\beta_{1}$ is the first (lag 1) GARCH parameter 
For this model to be well defined and conditional variance to be positive, the parameters must satisfy the following constraints:

$\alpha_{0}>0, \alpha_{1-0}, \beta_{-}>0$

\section{Asymmetric GARCH Models:}

The symmetric GARCH assumes that the good and bad news have the same effect in financial markets, but the fact is bad news has a more pronounced effect on volatility than good news of the same magnitude, in that case the symmetric specification such as GARCH is not appropriate, as the signs of the residuals or shocks have no effects on conditional volatility. However, the fact of financial volatility is that bad news (negative shocks) tends to have a larger impact on volatility than good news (positive shocks). In the case of equity returns, such asymmetries leads the leverage effects and the negative shocks cause the value of the firm to fall which raises the debt-equity ratio thereby increasing the risk of bankruptcy. Henceforth the shareholders perceive that the future cash flows are relatively more risky. The asymmetric models which include: $\operatorname{EGARCH}(1,1)$ and $\operatorname{TGARCH}(1,1)]$ are used to judge the leverage effect. The asymmetric model EGARCH $(1,1)$ is used in this paper to model asymmetric effect.

\section{EGARCH (1,1) Model:}

To capture the leverage effects, Nelson (1991) proposed the Exponential GARCH (EGARCH) model where the logarithm of the conditional variance is modelled as:

$\log \left(\sigma_{t}^{2}\right)=\alpha_{0}+\beta \log \left(\sigma_{t-1}^{2}\right)+\alpha_{1}\left(\varepsilon_{t-1} / \sigma_{t-1}\right)+\gamma\left(\varepsilon_{t-1} / \sigma_{t-1}\right)$

The variance has asymmetric effect if $y \neq 0$. Because of the log transformation, there is no possibility of a negative variance and the impact of the most recent residual is exponential rather than quadratic. The leverage effect term $(Y)$ is denoted as 'RESID $(-1) / @$ $\operatorname{SQRT}(\operatorname{GARCH}(-1))$ ' is the outcome. The term $\gamma$, accounts for the presence of the leverage effects, which makes the model asymmetric. If $y=0$, then the model is symmetric. If $\gamma$ is negative and statistically different from zero, it indicates the existence of the leverage effect.

\section{ARMA Model:}

ARMA model was introduced by Box and Jenkins in 1970. It also referred to as Box-Jenkins methodology composed of set of activities for identifying, estimating and diagnosing models with time series data. The model is often use for financial forecasting. Autoregressive (AR) and moving average (MA) models can be effectively combined together to form a general and useful class of time series models, known as the ARMA models. In ARMA model, the future value of a variable is a linear combination of past values and past errors, expressed as follows: 
Mathematically an ARMA $(p, q)$ model is represented as:

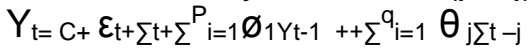

where, $Y_{t}$ is the actual value and $\varepsilon_{t}$ is the random error at $t, \varnothing$ and $\theta$ are the coefficients, $p$ and $q$ are integers that are often referred to as autoregressive and moving average, respectively.

$\varnothing=$ the autoregressive model's parameters,

$\theta=$ the moving average model's parameters.

$\mathrm{c}=\mathrm{a}$ constant

$\varepsilon=$ error terms (white noise).

Data Analysis and findings:

Results of ARCH Effect:

On the basis of $P$ value of all the lags it is clear that the $p$ value is higher then the significant level so the null hypothesis is accepted for all the Lags. We can conclude that there is no ARCH effect in our model and null hypothesis is accepted at $5 \%$ significant level.

Results of ARCH Effect: Table 3:

S\&P SENSEX 30: ARCH Effect Test at 5\% level of significance.

ARCH Effect Test

\begin{tabular}{cccccc}
\hline Lag & Score & C.V. & Value & Present? & $5.0 \%$ \\
\hline $\mathbf{1}$ & 9.79 & 3.84 & $0.2 \%$ & TRUE & \\
$\mathbf{2}$ & 12.53 & 5.99 & $0.2 \%$ & TRUE & \\
$\mathbf{3}$ & 12.55 & 7.81 & $0.6 \%$ & TRUE & \\
$\mathbf{4}$ & 27.28 & 9.49 & $0.0 \%$ & TRUE & \\
$\mathbf{5}$ & 33.35 & 11.07 & $0.0 \%$ & TRUE & \\
$\mathbf{6}$ & 36.30 & 12.59 & $0.0 \%$ & TRUE & \\
$\mathbf{7}$ & 38.83 & 14.07 & $0.0 \%$ & TRUE & \\
$\mathbf{8}$ & 40.52 & 15.51 & $0.0 \%$ & TRUE &
\end{tabular}

\section{Results of GARCH $(1,1)$}

The estimates of the $\mathrm{GARCH}(1,1)$ model are shown in Table 4. The coefficient (0.0575) of the ARCH effect is not significantly positive at $5 \%$ showing that news about previous volatility (past square residual terms) has explanatory power on current volatility. The GARCH effect coefficient $(0.0575)$ is also nt significantly positive at $5 \%$ level, which shows that past volatility of stock market return is not significantly, influencing current volatility. The sum of $\mathrm{ARCH}$ and $\mathrm{GARCH}$ coefficients $\alpha 1+\beta 1$ $>1(0.11512)$ is a measure of the persistence of variance, and that its value is lesser 
than 1 implies that there is no significant high persistence in volatility. As suggested by Engle and Bollerslev (1986), if a1 $+\beta=1$, a current shock persists indefinitely in conditioning the future variance. Since the sum of $a 1+\beta$ represents the change in response function of shocks to volatility persistence, a value greater than unity implies that response function of volatility increases with time and a value less than unity implies that shocks decline with time (Chou, 1988). Therefore, the above result indicates that shocks are not persistent in the NSE S\&P SENSEX 30.

Table 4:

GARCH $(1,1)$ Model for the S\&P Sensex 30 data:

\begin{tabular}{|llcll|}
\hline GARCH(1,1) & \multicolumn{3}{l|}{} \\
& Param & Value & & \\
& $\mu$ & 0.05993 & & \\
& $\alpha 0$ & 0.46735 & & \\
& $\alpha 1$ & 0.057563 & & \\
& $\beta 1$ & 0.057563 & & \\
Goodness-of-fit & & & & \\
LLF & AIC & CHECK & & \\
-803.786 & 1613.573 & 1 & & \\
Residuals (standardized) Analysis & & Kurtosis & ARCH? \\
AVG & STDEV & Skew & ThU \\
\hline
\end{tabular}

\section{Results of EGARCH $(1,1)$}

The EGARCH $(1,1)$ is an asymmetric model, which is used to investigate the existence of leverage effect in returns of the NSE S\&P SENSEX 30 . The estimates of the model are reported in Table 5. The asymmetric term ( $\mathrm{\gamma} 1)$ in the $\operatorname{EGARCH}(1,1)$ The asymmetric (leverage) effect captured by the parameter estimate $\mathrm{Y} 1$ is also statistically significant with negative sign, indicating that negative shocks imply a higher next period conditional variance than positive shocks of the same sign, which indicates the existence of leverage effects in the returns of the National stock Exchange S\&P SENSEX 30 index during the study period.

EGARCH $(1,1)$ Model for the S \& P Sensex 30 data:

\begin{tabular}{|lll|}
\hline EGARCH(1,1) & Param & Value \\
& $\boldsymbol{\mu}$ & 0.05993 \\
& $\mathbf{\alpha 0}$ & -2.04441 \\
& $\mathbf{\alpha 1}$ & -0.04501 \\
& V1 & -0.26402
\end{tabular}




\begin{tabular}{|c|c|c|c|c|}
\hline \multicolumn{5}{|c|}{ 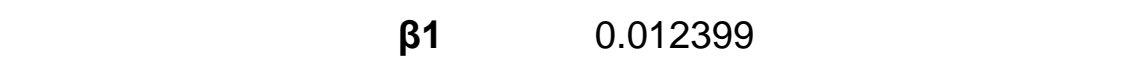 } \\
\hline \multicolumn{5}{|c|}{ Goodness-of-fit } \\
\hline LLF & AIC & \multicolumn{3}{|l|}{ CHECK } \\
\hline-1572.44063 & 3154.881 & \multicolumn{3}{|c|}{1} \\
\hline \multicolumn{5}{|c|}{ Residuals (standardized) Analysis } \\
\hline AVG & STDEV & Skew & Kurtosis & $\mathrm{ARCH}$ ? \\
\hline-0.00311577 & 2.13908 & -0.21854 & 1.012617 & TRUE \\
\hline
\end{tabular}

ARCH-LM Test: The ARCH-LM test results show no evidence of remaining ARCH effects.

The evidence of volatility in the market return may create barrier for investors.

Results: ARCH LM-test;

Null hypothesis: no ARCH effects.

data: \% Return of S \& P Sensex 30

Chi-squared $=43.502, \mathrm{df}=14, \mathrm{p}$-value $=6.67 \mathrm{e}-06$

\section{Auto Regressive Moving Average model (ARMA)}

ARMA $(p, q)$ is the process which combines AR series as well as MA series. $\theta$ are the coefficients, $p$ and $q$ are integers that are often referred to as autoregressive and moving average, respectively the value of these integer is zero respectively. Here sigma is the standard deviation of the model's residuals which is 1.508. The ARMA ( $p, q)$ process is detected by plotting correlogram of Auto Correlation Function (ACF) and Partial Auto Correlation Function (PACF) against lags, which shows declining curve as lag increases in both ACF and PACF cases as shown in fig.3. ACF and PACF both are showing short term autocorrelation.

ARMA $(1,1)$ Model for the S\&P Sensex 30 data:

\begin{tabular}{|c|c|c|c|c|}
\hline \multicolumn{5}{|l|}{$\operatorname{ARMA}(1,1)$} \\
\hline Param & \multicolumn{4}{|l|}{ Value } \\
\hline$\mu$ & \multicolumn{4}{|l|}{0.318} \\
\hline$\varphi 1$ & \multicolumn{4}{|l|}{0.000} \\
\hline$\theta 1$ & \multicolumn{4}{|l|}{0.000} \\
\hline$\sigma$ & \multicolumn{4}{|l|}{1.508} \\
\hline \multicolumn{5}{|c|}{ Goodness-of-fit } \\
\hline LLF & AIC & \multicolumn{3}{|l|}{ CHECK } \\
\hline-203.030 & 513.131 & \multicolumn{3}{|l|}{1.000} \\
\hline \multicolumn{5}{|c|}{ Residuals (standardized) Analysis } \\
\hline AVG & STDEV & Skew & Kurtosis & $\begin{array}{l}\text { ARCH } \\
\text { Effect }\end{array}$ \\
\hline $5.423 \mathrm{E}-17$ & $1.013 E+00$ & $-1.324 \mathrm{E}-01$ & $1.310 \mathrm{E}+00$ & False \\
\hline
\end{tabular}



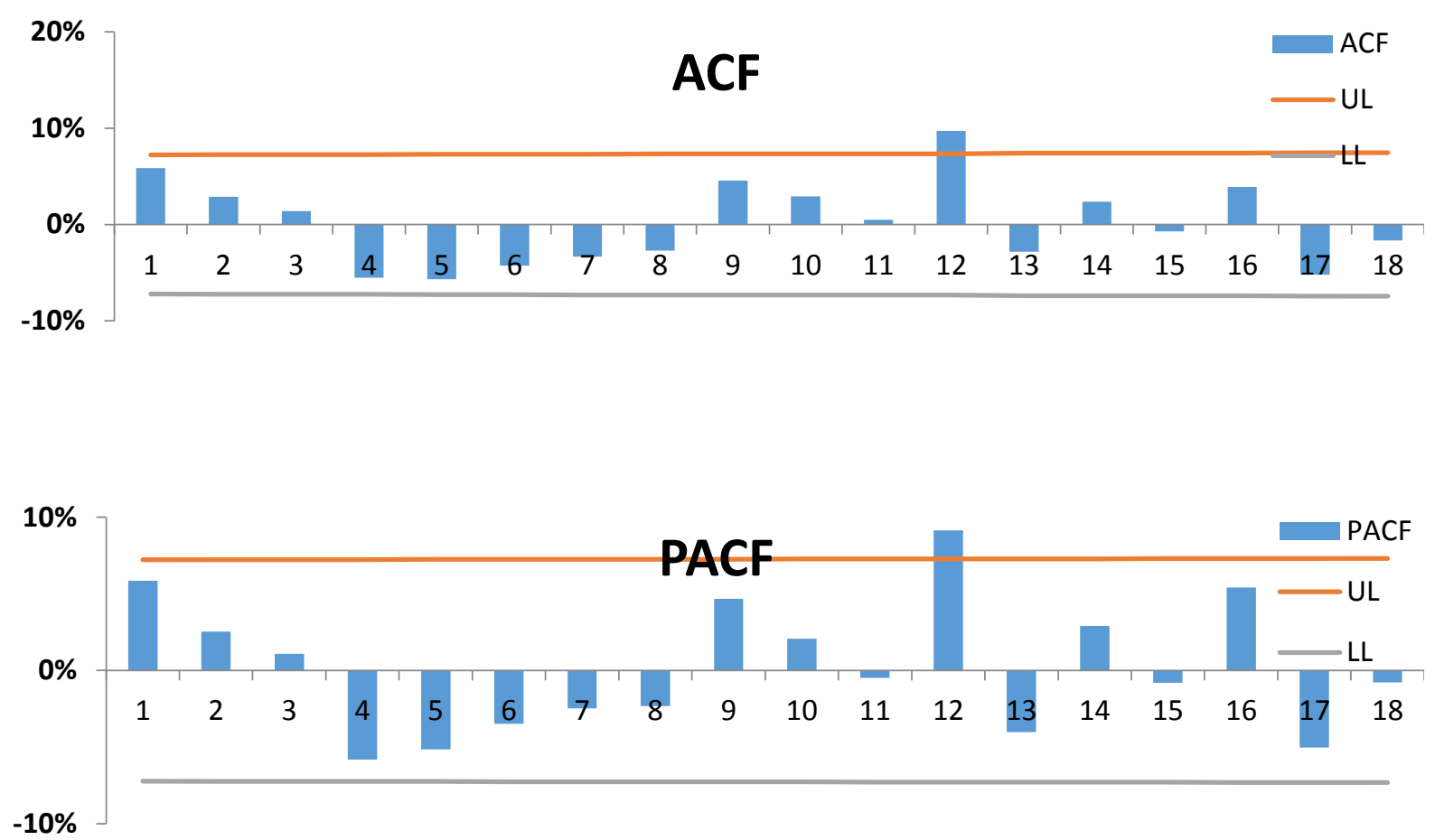

S\&P Sensex 30: The ACF and PACF correlogram for ARMA model.

Correlogram Analysis

\begin{tabular}{ccccccc}
\hline Lag & ACF & UL & LL & PACF & UL & LL \\
\hline $\mathbf{1}$ & $5.84 \%$ & $7.22 \%$ & $-7.22 \%$ & $5.86 \%$ & $7.22 \%$ & $-7.22 \%$ \\
$\mathbf{2}$ & $2.88 \%$ & $7.24 \%$ & $-7.24 \%$ & $2.54 \%$ & $7.23 \%$ & $-7.23 \%$ \\
$\mathbf{3}$ & $1.38 \%$ & $7.25 \%$ & $-7.25 \%$ & $1.08 \%$ & $7.23 \%$ & $-7.23 \%$ \\
$\mathbf{4}$ & $-5.52 \%$ & $7.25 \%$ & $-7.25 \%$ & $-5.82 \%$ & $7.24 \%$ & $-7.24 \%$ \\
$\mathbf{5}$ & $-5.67 \%$ & $7.27 \%$ & $-7.27 \%$ & $-5.15 \%$ & $7.24 \%$ & $-7.24 \%$ \\
$\mathbf{6}$ & $-4.29 \%$ & $7.30 \%$ & $-7.30 \%$ & $-3.47 \%$ & $7.25 \%$ & $-7.25 \%$ \\
$\mathbf{7}$ & $-3.34 \%$ & $7.31 \%$ & $-7.31 \%$ & $-2.48 \%$ & $7.25 \%$ & $-7.25 \%$ \\
$\mathbf{8}$ & $-2.70 \%$ & $7.32 \%$ & $-7.32 \%$ & $-2.32 \%$ & $7.26 \%$ & $-7.26 \%$ \\
$\mathbf{9}$ & $4.56 \%$ & $7.32 \%$ & $-7.32 \%$ & $4.68 \%$ & $7.26 \%$ & $-7.26 \%$ \\
$\mathbf{1 0}$ & $2.90 \%$ & $7.34 \%$ & $-7.34 \%$ & $2.07 \%$ & $7.27 \%$ & $-7.27 \%$ \\
$\mathbf{1 1}$ & $0.50 \%$ & $7.34 \%$ & $-7.34 \%$ & $-0.49 \%$ & $7.27 \%$ & $-7.27 \%$ \\
$\mathbf{1 2}$ & $9.72 \%$ & $7.34 \%$ & $-7.34 \%$ & $9.14 \%$ & $7.28 \%$ & $-7.28 \%$ \\
$\mathbf{1 3}$ & $-2.84 \%$ & $7.41 \%$ & $-7.41 \%$ & $-4.02 \%$ & $7.28 \%$ & $-7.28 \%$ \\
$\mathbf{1 4}$ & $2.37 \%$ & $7.42 \%$ & $-7.42 \%$ & $2.90 \%$ & $7.29 \%$ & $-7.29 \%$ \\
$\mathbf{1 5}$ & $-0.73 \%$ & $7.42 \%$ & $-7.42 \%$ & $-0.79 \%$ & $7.29 \%$ & $-7.29 \%$ \\
$\mathbf{1 6}$ & $3.87 \%$ & $7.42 \%$ & $-7.42 \%$ & $5.41 \%$ & $7.30 \%$ & $-7.30 \%$ \\
$\mathbf{1 7}$ & $-5.22 \%$ & $7.43 \%$ & $-7.43 \%$ & $-5.03 \%$ & $7.30 \%$ & $-7.30 \%$ \\
$\mathbf{1 8}$ & $-1.66 \%$ & $7.45 \%$ & $-7.45 \%$ & $-0.77 \%$ & $7.31 \%$ & $-7.31 \%$
\end{tabular}


The log returns do not exhibit strong interdependency, though lag order 1,4,12 and 16 showing marginal significance. The log-returns time series exhibit white-noise which also shown in white noise test of serial correlation.

\section{Conclusion}

This paper examined the volatility of returns on the National Stock Exchange index S\&P SENSEX 30. The preliminary analysis of data used reveals the non -stationary, normal distribution and variables show white noise process which shows serial correlation. Weak evidence of $A R C H$ effects in $B S E$ return series are shown by $A R C H$ effect test. To capture the volatility, GARCH $(1,1), \operatorname{EGARCH}(1,1)$ and ARMA models are used. The ARCH effect (a1) is significantly positive. The EGARCH $(1,1)$ model at $5 \%$ is showing that news about previous volatility has an explanatory power on current volatility for other models it was not found.

The GARCH effect $(\beta)$ is 0.11512 for $\operatorname{GARCH}(1,1)$ and negative for $\operatorname{EGARCH}(1,1)$ at $5 \%$ level, which shows that past volatility of stock market return is not significantly, influencing current volatility. The asymmetric models support the presence of leverage effects.

After estimation of the GARCH models, ARCH-LM test is used to test whether there the ARCH effect remains in the series. The ARCH-LM test results show no evidence of residual ARCH effects. The result of this study provides an indication of volatility for market regulators and policy makers in the Indian Stock Market and help them in there investing decisions.

\section{References:}

Aggarwal, R.; Inclan, C. and Leal, R. (1999),"Volatility in Emerging Stock Markets," Journal of Financial and Quantitative Analysis, 34(1): 33-55.

Akgiray AK (1989). Conditional heteroscedasticity in time series of stock returns: Evidence and forecasts. J. Bus., 62: 55-79.

Amadeus Wennström, "Volatility Forecasting Performance: Evaluation of GARCH type volatility models on Nordic equity indices", June 112014.

Balaban, E., Bayar, A. and Faff, R. (2005). Forecasting Stock Market Volatility: Further International Evidence.ASAC, Quebec, Canada.

Bekaert, G. and Harvey, C. R. (1997), "Emerging Market Volatility," Journal of Financial Economics, 43: 29-77.

Bollerslev, T. (1986). Generalized Autoregressive Conditional Heteroscedasticity. Journal of Econometrics, 31, 307-327. http://dx.doi.org/10.1016/0304-4076(86)90063-1 
Bollerslev, T., Chou, R., \& Kroner, F. (1992). ARCH modeling in finance. Journal of Econometrics, 52, 5-59. http://dx.doi.org/10.1016/0304-4076(92)90064-X

Brailsford, T. and Faff, R. (1996) An evaluation of volatility forecasting techniques, Journal of Banking and Finance, 20, 419-38.

Brooks, C., Burke, S.P. 1998. Forecasting exchange rate volatility using conditional variance models selected by information criteria, Economics Letters 61, 273-278.

Campbell, J.Y. and Hentschel, L. (1992), "No News is Good News: An Asymmetric Model of Changing Volatility in Stock Returns," Journal of Financial Economics, 31: 281-318.

Chen, N., Roll, R., \& Ross, S. (1986). Economic Forces and the Stock Market. Journal of Business, 59, 383-403. https://doi.org/10.1086/296344

Choo, C.W.C. (1999), Performance of GARCH Models in Forecasting Stock Market Volatility. Journal of Forecasting, 18, 333-334.

Chou,RY (1988),Volatility Persistence \& Stock Valuation: Some Emphirical Evidences using GARCH, Journal of Applied Econometrics 3(4), 274-294.

Curto, J.J.D.(2002). Modelling the volatility in the Portuguese Stock Market: A Comparative Study with German and US markets. Unpublished Phd Thesis, Lisbon University.

Dana Alnajjar, (2016), Modelling and Estimation of Volatility Using ARCH/GARCH Models in Jordan's Stock Market,Asian Journal of Finance \& Accounting,Volume 8, No. 1.

Emenike, K. O. \& Aleke, S. F. (2012). Modeling asymmetric volatility in the Nigerian stock exchange. European Journal of Business and Management, 4(12), 52-59.

Engle, R.F. (1982). Autoregressive conditional heteroscedasticity with estimates of variance of United Kingdom Inflation, Journal Econometrica, 50(4) 987-1008.

Engle, R.F., Focardi, S.M., \& Fabozzi, F.J. (2007). ARCH/GARCH Models in Applied Financial Econometrics. JWPR-026.

Franses, P.H. and Van Dijk, R. (1996). Forecasting stock market volatility using (non-linear) Garch models, Journal of Forecasting, 15, 229-35.

Gokcan S., (2000). Forecasting volatility of emerging stock markets: Linear versus Non-Linear GARCH models, Journal of Forecasting, 19, 499-504. 
Hojatallah Goudarzi, C. S. Ramanarayanan Pagan and Schwert (1990), Brailsford and Faff (1996) and Loudon et al. (2000) have shown evidences of conditional variance with asymmetric GARCH models.

Hojatallah Goudarzi, C. S. Ramanarayanan,2010, Modelling and Estimation of Volatility in the Indian Stock Market, International Journal of Business and Management, Volume 5, No 2.

Hojatallah, G. \& Ramanarayanan, C. S. (2010). Modeling and estimation of volatility in the Indian stock market. International Journal of Business and Management, 5(2), 85-98.

Ho-Jin Lee,2009, Forecasting Performance of Asymmetric GARCH Stock Market Volatility Models, Journal of International Economic Studies, ISSN 1598-2769, Vol. 13, No. 2.

Jayasuriya, S. (2002)," Does Stock Market Liberalization Affect the Volatility of Stock Returns: Evidence from Emerging Market Economies", Georgetown University Discussion Series, August.

Karmakar, M. (2005) "Modeling Conditional Volatility of the Indian Stock Markets", Vikalpa, 30, 3, $21-$ 37.

Karmakar, M. (2006) "Stock Market Volatility in the Long Run, 1961-2005", Economic and Political Weekly, May: 1796-1802

Kashif Saleem (2007)," Modeling Time Varying Volatility and Asymmetry of Karachi Stock Exchange (KSE)", International Journal of Economic Perspectives, Vol.1, No.1, pp 01-09.

Kummar S.S.S. (2006). Comparative performance of volatility forecasting models in indian markets. Decisions, Vol.33. 2.26-40.

Lastrapes, W. D. (1989). Exchange Rate Volatility and U.S. Monetary Policy: An ARCH Application. Journal of Money, Credit and Banking, 21, 66-77. https://doi.org/10.2307/1992578

Loudon, G., Watt, W. and Yadav, P. (2000) An empirical analysis of alternative parametric ARCH models, Journal of Applied Econometrics, 15, 117-36.

Ogum, G., Beer, F. and Nouyrigat, G. (2005). Emerging Equity Market Volatility: An Empirical Investigation of Markets in Kenya and Nigeria.Journal of Africa Business, 6(1), 139-154.

Pandey, A. (2005) "Volatility Models and their Performance in Indian Capital Markets", Vikalpa, 30, 2, : 27-46.

Pattanaik, S. and B. Chatterjee (2000) "Stock Returns and Volatility in India: An Empirical Puzzle?" Reserve Bank of India Occasional Papers, 21, 1: 37-60. 
Puja Padhi (2006), "Stock Market Volatility in India: A Case of Selected Scrips", Indian Institute of Capital Markets 9 th Capital Conference Paper, Social Science Research Network, www. ssrn.com, id.873985.

Schwert, W. (1989). 'Stock Volatility and Crash of 87.' Review of Financial Studies 3 (1): 77-102.

Shenbagaraman, P. (2003) "Do Futures and Options Trading Increase Stock Market Volatility?" Paper Published as Part of the NSE Research Initiative, available at www.nseindia.com.

Taylor, S. J. (1986). Modelling financial time series. John Wiley \& Sons, Chichester. Applied Financial Economics, 18, 1201-1208. http://dx.doi.org/10.1080/09603100701604225

Thomas, S. (1995) "An Empirical Characterization of the Bombay Stock Exchange", Ph. D. Thesis, University of Southern California.

Thomas, S. (1998) "Volatility Forecasting in Indian Financial Markets: Derivative Markets in India". New Delhi: Tata McGraw Hill

Tsay, R. S. (2010). Analysis of financial time series (2nd ed.). Indian Reprint, New Delhi, India: Wiley India (P.) Ltd.

Tudor, C. (2008). An Empirical Study on Risk-Return Tradeoff Using GARCH-Class Models: Evidence from Bucharest Stock Exchange. International Conference on Business and Economy ICBE Constanta - Romania, November 6-8.

Walter,A.D. (2005). A structural GARCH model: An application to portfolio risk management Unpublished PhD Thesis, University of Pretoria.

West, K.D., Cho, D. 1995. The predictive ability of several models of exchange rate volatility, Journal of Econometrics 69, 367-391.

Yaya, O.S., (2013). Nigerian Stock Index: A Search for Optimal GARCH, Central Bank of Nigeria Journal of Applied Statistics, 4, 69-85

Zivot Eric., and Wang. (2006). Modeling financial time series with s-plus, (2nd ed). Springer.

\section{Abbreviations:}

LLF-Uses the log Likeliyhood method to measure goodness of fit

AIC-Akaike Information criterion to measure goodness of fit

Check-stationary and positive variance

AVG-Average

STDEV-Standard Deviation 
Skew-Skewness

Kurtosis-Kurtosis

Noise-White noise test

ACF-Auto Correlation Function

PACF-Partial Auto Correlation Function 